\title{
Widespread changes of white matter microstructure in obsessive-compulsive disorder: Effect of drug status
}

\author{
Francesco Benedetti ${ }^{\mathrm{a}, \mathrm{b}, *}$, Chiara Giacosa ${ }^{\mathrm{a}, \mathrm{b}, 1}$, Daniele Radaelli ${ }^{\mathrm{a}, \mathrm{b}}$ \\ Sara Poletti ${ }^{\mathrm{a}, \mathrm{b}}$, Elena Pozzi ${ }^{\mathrm{a}, \mathrm{b}}$, Sara Dallaspezia ${ }^{\mathrm{a}, \mathrm{b}}$, Andrea Falini ${ }^{\mathrm{b}, \mathrm{c}}$, \\ Enrico Smeraldi ${ }^{\mathrm{a}, \mathrm{b}}$
}

\author{
${ }^{a}$ Department of Clinical Neurosciences, Scientific Institute and University Vita-Salute San Raffaele, Milano, Italy \\ ${ }^{\mathrm{b}}$ Centro di Eccellenza Risonanza Magnetica ad Alto Campo (C.E.R.M.A.C.), Milano, Italy \\ ${ }^{c}$ Department of Neuroradiology, Scientific Institute and University Vita-Salute San Raffaele, Milano, Italy
}

Received 15 December 2011; received in revised form 29 May 2012; accepted 3 July 2012

\author{
KEYWORDS \\ White matter; \\ Obsessive-compulsive \\ disorder; \\ OCD drug treatment; \\ Diffusion-tensor \\ imaging
}

\begin{abstract}
Diffusion tensor imaging (DTI) allows the study of white matter (WM) structure. Literature suggests that WM structure could be altered in obsessive-compulsive disorder (OCD) proportional to the severity of the disease. Heterogeneity of brain imaging methods, of the studied samples, and of drug treatments make localization, nature, and severity of the WM abnormalities unclear. We applied Tract-Based Spatial Statistics (TBSS) of DTI measures to compare fractional anisotropy (FA), mean, axial, and radial diffusivity of the WM skeleton in a group of 40 consecutively admitted inpatients affected by severe OCD (18 drug-naive, and 22 with an ongoing drug treatment) and 41 unrelated healthy volunteers from the general population. Data were analyzed accounting for the effects of multiple comparisons, and of age, sex, and education as nuisance covariates. Compared to controls, OCD patients showed a widespread reduction of FA with a concurrent increase of mean and radial diffusivity. In no brain areas patients had higher FA or lower diffusivity values than controls. These differences were observed in drug-treated patients compared to drug-naive patients and healthy controls, which in turn did not differ among themselves in any DTI measure. Reduced FA with increased mean and radial diffusivity suggests significant changes in myelination of WM tracts, without axonal loss. Drug treatments could modify the structure of cell membranes and myelin sheaths by influencing cellular lipogenesis, cholesterol homeostasis, autophagy, oligodendrocyte differentiation and remyelination. Changes of DTI
\end{abstract}

*Corresponding author at: Istituto Scientifico Ospedale San Raffaele, Department of Clinical Neurosciences, San Raffaele Turro, Via Stamira d'Ancona 20, Milano, Italy. Tel.: + 39022643 3156; fax: + 390226433265.

E-mail address: benedetti.francesco@hsr.it (F. Benedetti).

${ }^{1}$ Current affiliation: Department of Psychology, Concordia University, Montreal, Canada. 
measures in drug-treated OCD patients could reflect pathophysiological underpinnings of $O C D$, or a yet unexplored part of the mechanism of action of drugs.

(c) 2012 Elsevier B.V. and ECNP. All rights reserved.

\section{Introduction}

Brain imaging and neuropsychological studies of the possible biological underpinnings of obsessive-compulsive disorder $(O C D)$ point toward failures in the cortical control of frontostriatal neural circuits (Chamberlain et al., 2005; Fineberg et al., 2010), and suggest that the abnormal neuropsychological performances observed in OCD patients could be due to abnormal structure and function of several cortical regions and of basal ganglia. Morphological alterations are paralleled by abnormal functional responses to cognitive tasks (Remijnse et al., 2006; van den Heuvel et al., 2005), and by an increased metabolic activity of basal ganglia which tends to decrease and normalize after successful treatment (El Mansari and Blier, 2006; Linden, 2006). Abnormal activation patterns involve the interactions among the brain structures: recent BOLD fMRI studies of functional connectivity showed either increased connectivity among fronto-striatal structures in resting conditions (Sakai et al., 2010) and in response to tasks that elicit emotional/motivational responses (Stern et al., 2011), or mixed pictures of increased and decreased connectivity among different brain structures (Harrison et al., 2009; Jang et al., 2010; Zhang et al., 2011) or across different tasks (Fitzgerald et al., 2010).

An altered signal communication between brain networks could be associated with changes of white matter (WM) structure. Brain imaging studies hold significant promise for the investigation of WM in OCD, as suggested by the possibility to develop OCD symptoms after white matter lesions (Fontenelle et al., 2009), and by studies showing either decreased (Duran et al., 2009; Koprivova et al., 2009; van den Heuvel et al., 2009) or increased (Atmaca et al., 2010; Park et al., 2011; Togao et al., 2010) WM volumes in psychiatric OCD patients.

The structure of normal appearing WM can be studied with diffusion tensor magnetic resonance imaging (DTI). DTI measures the extension and direction of water diffusivity and provides indices of WM integrity which could be sensitive to the subtle pathological changes associated with psychiatric conditions (Le Bihan, 2003). Given the microscopic structure of WM, in normal conditions the integrity of myelinated axons limits the diffusion of water in directions other than along the axis of the fiber. This tendency to diffuse in one direction as opposed to all others, termed anisotropy, can be estimated through the application of diffusion-sensitizing gradients and the calculation of elements of the diffusion tensor matrix, i.e. the three eigenvalues $\lambda_{1}, \lambda_{2}$ and $\lambda_{3}$. Mean diffusivity (MD, average of $\lambda_{1}, \lambda_{2}$ and $\lambda_{3}$ ) is a measure of the average molecular motion, independent of tissue directionality. Studies in WM pathologies involving disruption of myelin sheaths (Horsfield and Jones, 2002) showed that a decrease of the tendency to diffuse along the principal direction $\left(\lambda_{1}\right)$ of the fiber (axial diffusivity, $A D$ ) suggests axonal loss or loss of bundle coherence, while an increase in diffusivity perpendicular to axonal walls (the average of $\lambda_{2}$ and $\lambda_{3}$, radial diffusivity (RD) suggests disrupted myelination (Song et al., 2002). Fractional anisotropy (FA) values range between 0 , when water motion is random in all directions, and 1 , when the directional selectivity of water motion is maximal. FA can reflect the structure of axonal cell membranes and myelin sheaths, with high FA values in heavily myelinated tracts (Kochunov et al., 2007).

DTI studies in adult OCD patients gave contrasting, albeit statistically significant, results. Fractional anisotropy was reported to be either significantly decreased (Bora et al., 2011; Chiu et al., 2011; Fontenelle et al., 2011; Garibotto et al., 2010; Nakamae et al., 2011; Oh et al., 2011; Saito et al., 2008; Szeszko et al., 2005) or increased (Cannistraro et al., 2007; Li et al., 2011; Nakamae et al., 2008; Yoo et al., 2007; Zarei et al., 2011), or either increased or decreased in different brain areas (Lochner et al., 2012; Menzies et al., 2008) or in subgroups with different symptomatological dimensions ( $\mathrm{Ha}$ et al., 2009). Surprisingy, opposite effects were detected in the same WM tracts in the different studies. Regions where a reduction of FA was observed included corpus callosum, cingulum bundle, anterior and posterior limb of the internal capsule, anterior thalamic radiation, superior longitudinal fasciculus, inferior fronto-occipital fasciculus, and the WM of parietal and superior frontal regions. Regions where FA was found to be increased included corpus callosum, cingulum bundle, anterior and posterior limb of the internal capsule, semioval center, and the WM of parietal regions and superior, middle and medial frontal gyrus.

All these studies, except one performed in drug naïve patients (Yoo et al., 2007), have been performed on mixed samples including together patients who were either currently taking drugs, drug-free, or drug-naïve, and without comparing these conditions. This led us to hypothesize that a possible reason for the failure to reach a shared knowledge about the relationship between OCD and WM structure could be the confounding and overlooked influence of drug status. To precise the extent and the quality, if any, of possible influences of drug status on WM abnormalities in OCD, here we studied the DTI measures of WM structure by means of tract based spatial statistics (TBSS) in two homogeneous samples of patients affected by OCD and either treated with psychotropic drugs, or drug-naïve, and in healthy controls.

\section{Experimental procedures}

\subsection{Sample, treatment and clinical assessment}

We studied 40 inpatients ( 26 males and 14 females) affected by obsessive-compulsive disorder (DSM-IV criteria, SCID-I interview) and consecutively referred to our hospital unit. Eighteen patients were drug-naïve, and 22 were being administered a drug treatment upon clinical need (including sertraline, fluvoxamine, citalopram, paroxetine, clomipramine, risperidone, olanzapine, haloperidol; 
see detailed description in Supplementary Table S1; all these patients were taking benzodiazepines). Exclusion criteria were: additional diagnoses on axis I, mental retardation on axis II, pregnancy, major medical and neurological disorders, history of drug or alcohol abuse or dependency. Physical examination, laboratory tests and electrocardiograms were performed at admission. Forty-one healthy subjects with no previous history of psychiatric, neurological and systemic disorders served as controls. After complete description of the study to the subjects a written informed consent was obtained. The local ethical committee approved the study protocol.

Severity of symptoms was rated on the Yale-Brown ObsessiveCompulsive Scale (Y-BOCS) (Goodman et al., 1989) by trained raters, blind to the results of the DTI study. Patients presented various contents of obsessions and compulsions, usually mixed (e.g., aggressive/checking, contamination/washing/cleaning, symmetric/ ordering/counting, hoarding). The clinical assessment was performed by trained raters, blind to the results of the DTI analysis.

\subsection{Image acquisition}

Diffusion tensor imaging was performed on a 3.0 Tesla scanner (Gyroscan Intera, Philips, Netherlands) using SE Eco-planar imaging (EPI) and the following parameters: TR/TE $=8753.89 / 58 \mathrm{~ms}$, FoV (mm), 231.43 (ap), 126.50 (fh), 240.00 (rl); acquisition matrix $2.14 \times 2.71 \times 2.31$; 55 contiguous, $2.3-\mathrm{mm}$ thick axial slices reconstructed with in-plane pixel size $1.88 \times 1.87 \mathrm{~mm}^{2}$; SENSE acceleration factor $=2 ; 1$ b0 and 35 non-collinear directions of the diffusion gradients; $b$ value $=900 \mathrm{~s} / \mathrm{mm}^{2}$. Fat saturation was performed to avoid chemical shift artifacts. On the same occasion and using the same magnet 22 Turbo Spin Echo (TSE), T2 axial slices (TR=3000 ms; $\mathrm{TE}=85 \mathrm{~ms}$; flip angle $=90^{\circ}$; turbo factor $15 ; 5-\mathrm{mm}$-thick, axial slices with a $512 \times 512$ matrix and a $230 \times 230 \mathrm{~mm}^{2}$ field of view) were acquired to rule out brain lesions.

\subsection{Data processing and analysis}

Image analyses and tensor calculations were done using the "Oxford Center for Functional Magnetic Resonance Imaging of the Brain Statistical Library" (FSL 4.1.4; http://www.fmrib.ox.ac.uk/) (Smith et al., 2004; Woolrich et al., 2009). First, each of the 35 DTI volumes was affine registered to the T2-weighted $b=0$ volume using FMRIB's Linear Image Registration Tool (FLIRT) (Jenkinson and Smith, 2001). This corrected for motion between scans and residual eddy-current distortions present in the diffusion-weighted images. In addition, trained reasearchers blind to diagnosis manually inspected each volume of each image to check for head motion artifacts: scans rated as 0 (none) had little or no detectable motion artifact, those rated as 1 (mild) had enough detectable motion to result in subtle concentric bands, 2 (moderate) had significant banding while those rated as 3 (severe) were so extreme that the data was deemed unreliable for analyses (Blumenthal et al., 2002). A representative image of an axial slice, taken at $z=27$, of all the 36 volumes of a representative DTI scan, also including the table of the user defined directions to which each image corresponds, is provided in Supplementary Figure S1.

After removal of nonbrain tissue (Smith, 2002), least-square fits were performed to estimate the FA, eigenvector, and eigenvalue maps. MD was defined as the mean of all three eigenvalues $\left[\left(\lambda_{1}+\lambda_{2}+\lambda_{3}\right) / 3\right], \mathrm{AD}$ as the principal diffusion eigenvalue $\left(\lambda_{1}\right)$, and $\mathrm{RD}$ as the mean of the second and third eigenvalues $\left[\left(\lambda_{2}+\lambda_{3}\right) / 2\right]$. Next, all individuals' FA volumes were skeletonized and transformed into a common space as used in Tract-Based Spatial Statistics (Smith et al., 2006, 2007). TBSS focuses on the centers of all fiber bundles that are common to the participants (the most compact WM skeleton), thus improving the probability that the given spatial voxels contain data from the same part of the same WM tract of each participant. Briefly, all volumes were nonlinearly warped to the FMRIB58_FA template supplied with FSL (http://www.fmrib.ox. ac.uk/) and normalized to the Montreal Neurological Institute (MNI) space, by use of local deformation procedures performed by FMRIB's Non-Linear Image Registration Tool (FNIRT) (http://www. fmrib.ox.ac.uk/), a nonlinear registration toolkit using a b-spline representation of the registration warp field (Rueckert et al., 1999). The common template used in the present study is a high-resolution average of 58 FA volumes from healthy male and female subjects aged 20-50 yr. All warped FA volumes were visually inspected for accuracy, which is especially pertinent when analyz ing datasets with broad age ranges with relatively large interindivi dual variability in brain size and architecture. FNIRT has been shown to perform the native-to-standard warping adequately across several age groups, including children and adolescents (Westlye et al., 2010). Next, a mean FA volume of all subjects was generated and thinned to create a mean FA skeleton representing the centers of all common tracts. We thresholded and binarized the mean skeleton at FA $>0.20$ to reduce the likelihood of partial voluming in the borders between tissue classes, yielding a mask of 137,833 WM voxels. Individual FA values were warped onto this mean skeleton mask by searching perpendicular from the skeleton for maximum FA values. Using maximum FA values from the centers of the tracts further minimizes confounding effects attributable to partial volum ing (Smith et al., 2006). The resulting tract invariant skeletons for each participant were fed into voxelwise permutation-based crosssubject statistics. Similar warping and analyses were used on MD, $A D$, and RD data sampled from voxels with $F A>0.20$.

We ran a permutation-based non-parametric inference to investigate the differences between the three groups of healthy controls and patients, split into drug treated and drug-naïve ones. We accounted for the effects of nuisance covariates known to influence WM structure: age (Kochunov et al., 2007), sex (Herting et al., 2011), and education (Engvig et al., 2011). Voxelwise DTI analyses were performed using nonparametric permutation-based testing (Nichols and Holmes, 2002) as implemented in Randomize in FSL. We tested for linear effects of group (three groups: healthy controls, drug-naïve $O C D$, drug-treated $O C D$ ) on $F A, M D, A D$, and $\mathrm{RD}$ across the WM skeleton with general linear models (GLM) while using sex, age, and education as covariates. Threshold-free cluster enhancement (TFCE) (Smith and Nichols, 2009) was used to avoid defining arbitrary cluster-forming thresholds and smoothing levels. TFCE is particularly useful when the spatial correlation length of signal exceeds that of noise, as it is expected when studying WM tracts. It can be seen as a generalization of the cluster mass statistics (Bullmore et al., 1999), using spatial neighborhood information in a non-linear image processing to increase sensitivity and boosting the height of spatially distributed signals, without changing the location of their maxima. Voxelwise levels of significance, corrected for multiple comparisons, were then calculated with a standard permutation testing by building up the null distribution (across permutation of the input data) of the maximum (across voxels) TFCE scores, and then using the 95th percentile of the null distribution to threshold signals at corrected $p<0.05$. The data were tested against an empirical null distribution generated by 5000 permutations for each contrast, thus providing statistical maps fully corrected for multiple comparisons across space. Corrected $p<0.05$ in a minimum cluster size of $k=100$ was considered significant.

Clinical and demographic characteristics of patients and controls were compared with one-way ANOVAs (StatSoft, 1995).

\section{Results}

Clinical and demographic characteristics of the sample, and levels of significance of the observed differences, are shown in Table 1. Years of education were higher in controls than in 
Table 1 Clinical and demographic characteristics of the sample, and levels of significance of the observed differences (one-way ANOVA between the three groups of controls and drug-naïve and drug treated patients, or between drug-naïve and drug treated patients). Values are means \pm SD.

\begin{tabular}{|c|c|c|c|c|c|c|c|}
\hline & $\begin{array}{l}\text { All patients } \\
\text { together }\end{array}$ & $\begin{array}{l}\text { Drug-naïve } \\
\text { patients }\end{array}$ & $\begin{array}{l}\text { Drug-treated } \\
\text { patients }\end{array}$ & Controls & $F$ or $\chi$ & d.f. & $p$ \\
\hline $\operatorname{Sex}(M / F)$ & $26 / 14$ & $11 / 7$ & $15 / 7$ & $20 / 21$ & 2.17 & 1 & 0.141 \\
\hline Age & $33.88 \pm 10.73$ & $34.06 \pm 11.10$ & $33.73 \pm 10.67$ & $33.76 \pm 13.19$ & 0.005 & 2.78 & 0.995 \\
\hline Education (yr) & $13.08 \pm 3.24$ & $14.11 \pm 3.04$ & $12.23 \pm 3.22$ & $15.78 \pm 2.73$ & 10.298 & 2.78 & $<0.001$ \\
\hline Head motion artifacts & $0.95 \pm 0.81$ & $1.11 \pm 0.96$ & $0.81 \pm 0.66$ & $0.95 \pm 0.84$ & 0.626 & 2.78 & 0.538 \\
\hline Age at onset & $14.05 \pm 7.50$ & $14.83 \pm 7.79$ & $13.41 \pm 7.50$ & - & 0.351 & 1.38 & 0.556 \\
\hline Y-BOCS total score & $31.22 \pm 5.57$ & $30.11 \pm 6.18$ & $32.14 \pm 4.98$ & - & 1.318 & 1.38 & 0.258 \\
\hline Y-BOCS obsessions score & $16.13 \pm 2.44$ & $15.89 \pm 2.40$ & $16.32 \pm 2.50$ & - & 0.302 & 1.38 & 0.586 \\
\hline $\begin{array}{l}\text { Y-BOCS compulsions } \\
\text { score }\end{array}$ & $15.35 \pm 3.34$ & $14.78 \pm 3.95$ & $15.82 \pm 2.76$ & - & 0.957 & 1.38 & 0.334 \\
\hline Duration of illness (yr) & $19.05 \pm 9.94$ & $17.78 \pm 8.75$ & $20.10 \pm 10.92$ & - & 0.529 & 1.38 & 0.471 \\
\hline
\end{tabular}

both drug-naïve and drug-treated patients, which did not significantly differ from each other. No other difference among groups was statistically significant.

\subsection{Effect of diagnosis}

We observed widespread reductions of fractional anisotropy, and increases of mean and radial diffusivities, in patients compared to controls (Table 2). No significant difference of axial diffusivity was observed.

Areas of significant difference for FA (Figure 1) included the cingulated bundle, the posterior thalamic radiation, the inferior longitudinal fasciculus, the superior longitudinal fasciculus, and the anterior limb of internal capsule in the right hemisphere; the body of corpus callosum and the superior corona radiata in the left hemisphere, and bilateral inferior fronto-occipital fasciculus, uncinate fasciculus, anterior thalamic radiations, anterior corona radiata (ACR), extending to the forceps minor.

$M D$ increased in almost the same regions: the inferior fronto-occipital fasciculus, forceps minor and superior longitudinal fasciculus bilaterally, the left anterior thalamic radiation, uncinate fasciculus and external capsule, and the right inferior longitudinal fasciculus. The only cluster of increased RD was located in the left hemisphere and involved the superior longitudinal fasciculus, the cingulate bundle, the forceps minor, and the superior corona radiata, whereas bilaterally the inferior fronto-occipital fasciculus and the anterior thalamic radiations.

\subsection{Effect of drug treatment}

No significant difference of either FA, MD, or RD were observed between drug-naiive patients and healthy subjects, while drug treated patients showed widespread differences in DTI measures both from drug-naïve patients and from healthy participants (Figures 2 and 3 ).

Compared to healthy controls (Table 3) drug-treated patients showed decreased FA in the left hemisphere (anterior corona radiate, forceps minor, inferior frontooccipital fasciculus and uncinate fasciculus), and increased
MD involving: left anterior corona radiate and cingulum bundle, inferior longitudinal fasciculus and forceps major, right superior longitudinal fasciculus, forceps minor and uncinate fasciculus, and bilateral inferior fronto-occipital fasciculus. Augmented values of RD were also found in anterior corona radiata, forceps minor, left uncinate fasciculus and inferior fronto-occipital fasciculus.

Compared to drug-naïve patients, drug-treated patients presented significantly lower values of FA in the right inferior fronto-occipital, superior and inferior longitudinal fasciculi; with decreases of RD in the genu of corpus callosum, forceps minor and around the left cingulate gyrus.

\section{Discussion}

We observed widespread changes of WM microstructure in drug-treated, but not in drug-naïve, patients with OCD. Drug-treated patients showed reduced FA and increased MD and RD compared to both drug-naive patients and healthy controls. These two latter groups, on the other hand, did not significantly differ among themselves. This suggests that the WM changes observed in OCD patients might be related to drug status. Drug status could have influenced the contrasting reports of WM abnormalities in previous studies of mixed samples of drug-naïve and drug-treated OCD patients (see Section 1).

The few available evidences confirm that psychotropic drugs can change WM microstructure. In patients with bipolar disorder, current medication load was inversely correlated with FA (Versace et al., 2008). In depressed elderly patients, tricyclic or selective serotonergic antidepressants increased WM hyperintensities (Steffens et al., 2008), and a one-year treatment with sertraline caused a significant decrease of FA which was proportional to the reduction of depression severity (Taylor et al., 2011). Antipsychotics reduce the number of glial cells in monkeys, although oligodendrocytes are only marginally affected (Konopaske et al., 2008). A study in 13 drug-naïve patients with OCD showed that a three-months treatment with citalopram significantly decreased OCD symptomatology, and also reduced $\mathrm{FA}$ in the posterior thalamic radiadion in 
Table 2 Comparison of OCD patients with healthy controls. Values of the DTI measures of FA, MD and RD (means \pm SD) are given for all groups (controls, drug-naive, and drugtreated patients), in the WM regions where the whole group of patients significantly differed from healthy controls. Dimensions of clusters (number of voxels, mm ${ }^{3}$ ), Z-values, and involved WM tracts are shown for regions showing maximal differences of TBSS values (signal peaks, MNI coordinates) between patients and controls.

\begin{tabular}{|c|c|c|c|c|c|}
\hline DTI measure & Controls & Patients & Number of voxels & $\begin{array}{l}\text { Signal peak }(x, y, z) \text { and } \\
\text { corresponding } Z \text { values }\end{array}$ & White matter tracts \\
\hline \multirow[t]{5}{*}{$\begin{array}{l}\text { Fractional anisotropy } \\
\text { (patients }<\text { controls) }\end{array}$} & \multirow[t]{5}{*}{$0.50221 \pm 0.111728$} & \multirow[t]{5}{*}{$\begin{array}{l}\text { All patients: } 0.478071 \pm 0.113806 \\
\text { Drug-naïve: } 0.483702 \pm 0.113969 \\
\text { Drug-treated: } 0.473463 \pm 0.114214\end{array}$} & 3181 & $\begin{array}{l}272614 \\
Z=2.400\end{array}$ & $\begin{array}{l}\text { Anterior corona radiata } \mathrm{R} \\
\text { Inferior fronto-occipital fasciculus } \mathrm{R} \\
\text { Anterior limb of internal capsule } \mathrm{R} \\
\text { Anterior thalamic radiation } \mathrm{R} \\
\text { Uncinate fasciculus } \mathrm{R} \\
\text { Forceps minor }\end{array}$ \\
\hline & & & 1419 & $\begin{array}{l}-20366 \\
Z=2.245\end{array}$ & $\begin{array}{l}\text { Anterior corona radiata } L \\
\text { Anterior thalamic radiation } L \\
\text { Uncinate fasciculus } L \\
\text { Forceps minor } \\
\text { Inferior fronto-occipital fasciculus } L\end{array}$ \\
\hline & & & 1325 & $\begin{array}{l}16-4039 \\
Z=2.605 \\
\end{array}$ & $\begin{array}{l}\text { Cingulate bundle } \mathrm{R} \\
\text { Superior longitudinal fasciculus } \mathrm{R}\end{array}$ \\
\hline & & & 281 & $\begin{array}{l}38-48-2 \\
Z=2.366\end{array}$ & $\begin{array}{l}\text { Posterior thalamic radiation } \mathrm{R} \\
\text { Inferior fronto-occipital fasciculus R } \\
\text { Inferior longitudinal fasciculus R }\end{array}$ \\
\hline & & & 162 & $\begin{array}{l}-13131 \\
Z=2.003\end{array}$ & $\begin{array}{l}\text { Body of corpus callosum } \\
\text { Superior corona radiata } \mathrm{L}\end{array}$ \\
\hline \multirow[t]{4}{*}{$\begin{array}{l}\text { Mean diffusivity } \\
\text { (patients > controls) }\end{array}$} & \multirow[t]{4}{*}{$7.29 \pm 0.38$} & $\begin{array}{l}\text { All patients: } 7.50 \pm 0.38 \\
\text { Drug-naïve: } 7.44 \pm 0.38 \\
\text { Drug-treated: } 7.56 \pm 0.40\end{array}$ & 10,878 & $\begin{array}{l}-29365 \\
Z=2.257\end{array}$ & $\begin{array}{l}\text { Inferior fronto-occipital fasciculus } L \\
\text { Anterior thalamic radiation } L \text {, } \\
\text { Uncinate fasciculus } L \\
\text { Superior longitudinal fasciculus } L \\
\text { Forceps minor } \\
\text { External capsule } L\end{array}$ \\
\hline & & & 3787 & $\begin{array}{l}18-5942 \\
Z=2.257 \\
\end{array}$ & $\begin{array}{l}\text { Inferior fronto-occipital fasciculus } \mathrm{R} \\
\text { Superior longitudinal fasciculus R }\end{array}$ \\
\hline & & & 2047 & $\begin{array}{l}31329 \\
Z=2.149\end{array}$ & $\begin{array}{l}\text { Inferior fronto-occipital fasciculus } \mathrm{R} \\
\text { Forceps minor }\end{array}$ \\
\hline & & & 138 & $\begin{array}{l}5-623 \\
>Z=1.471\end{array}$ & $\begin{array}{l}\text { Inferior fronto-occipital fasciculus } \mathrm{R} \\
\text { Inferior longitudinal fasciculus } \mathrm{R}\end{array}$ \\
\hline $\begin{array}{l}\text { Radial diffusivity } \\
\text { (patients }>\text { controls) }\end{array}$ & $5.27 \pm 0.64$ & $\begin{array}{l}\text { All patients: } 5.51 \pm 0.66 \\
\text { Drug-naïve: } 5.43 \pm 0.67 \\
\text { Drug-treated: } 5.58 \pm 0.66\end{array}$ & 13,140 & $\begin{array}{l}-21-4241 \\
Z=2.284\end{array}$ & $\begin{array}{l}\text { Superior longitudinal fasciculus } L \\
\text { Cingulate bundle } L \\
\text { Forceps minor } \\
\text { Inferior fronto occipital fasciculus } L / R \\
\text { Superior corona radiata } L \\
\text { Anterior thalamic radiation } L / R\end{array}$ \\
\hline
\end{tabular}




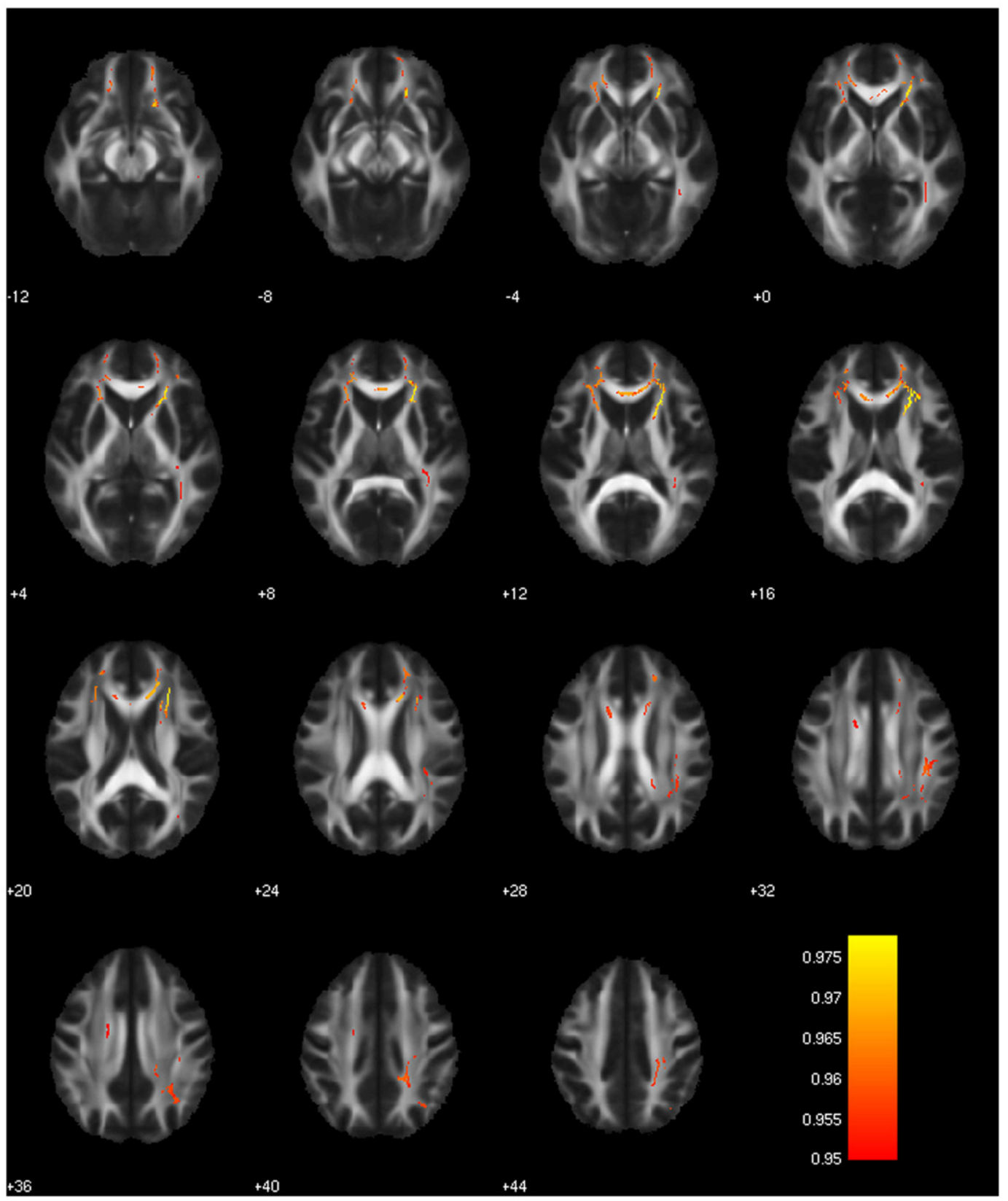

Figure 1 White matter areas where patients had significantly lower values of fractional anisotropy (FA) than controls. Voxels of significant difference are shown on the mean FA template of the studied sample. The colorbar refers to $1-p$ values for the observed differences. Group differences are mapped onto the mean FA brain template. Numbers are $z$ coordinates in the standard Montreal Neurological Institute (MNI) space. Images are in neurologic convention (left side of the brain is represented on the left side of the pictures). (For interpretation of the references to color in this figure legend, the reader is referred to the web version of this article.)

the right parietal lobe, thus normalizing abnormally higher baseline values (Yoo et al., 2007).

The pattern of abnormal findings that we described has been previously observed in neurological conditions associated to inflammation, degeneration, demyelination, or dysmyelination (Alexander et al., 2007). Given that an increase of radial diffusivity is thought to signify increased space between fibers, reduced FA with increased MD and RD is often interpreted as a sign of disrupted integrity of myelin sheaths due to demyelination or dysmyelination injury (Song et al., 2002). However, no diffusion measure is currently specific to any physiological or pathological process. Changes of FA can be due to a number of factors affecting local diffusivity, such as bundle coherence, crossing fibers, or water concentration (Chao et al., 2009; Pierpaoli et al., 2001; Rose et al., 2008). Several factors such as increases in myelination, or microscopic deficits of axonal structures, or decreases in axonal diameter, packing density, and fiber branching may cause higher directionality and contribute to higher FA in the regions where fibers cross: such increases of FA have been associated with neuropsychological deficits in neurological conditions (Hoeft et al., 2007). Observing a 


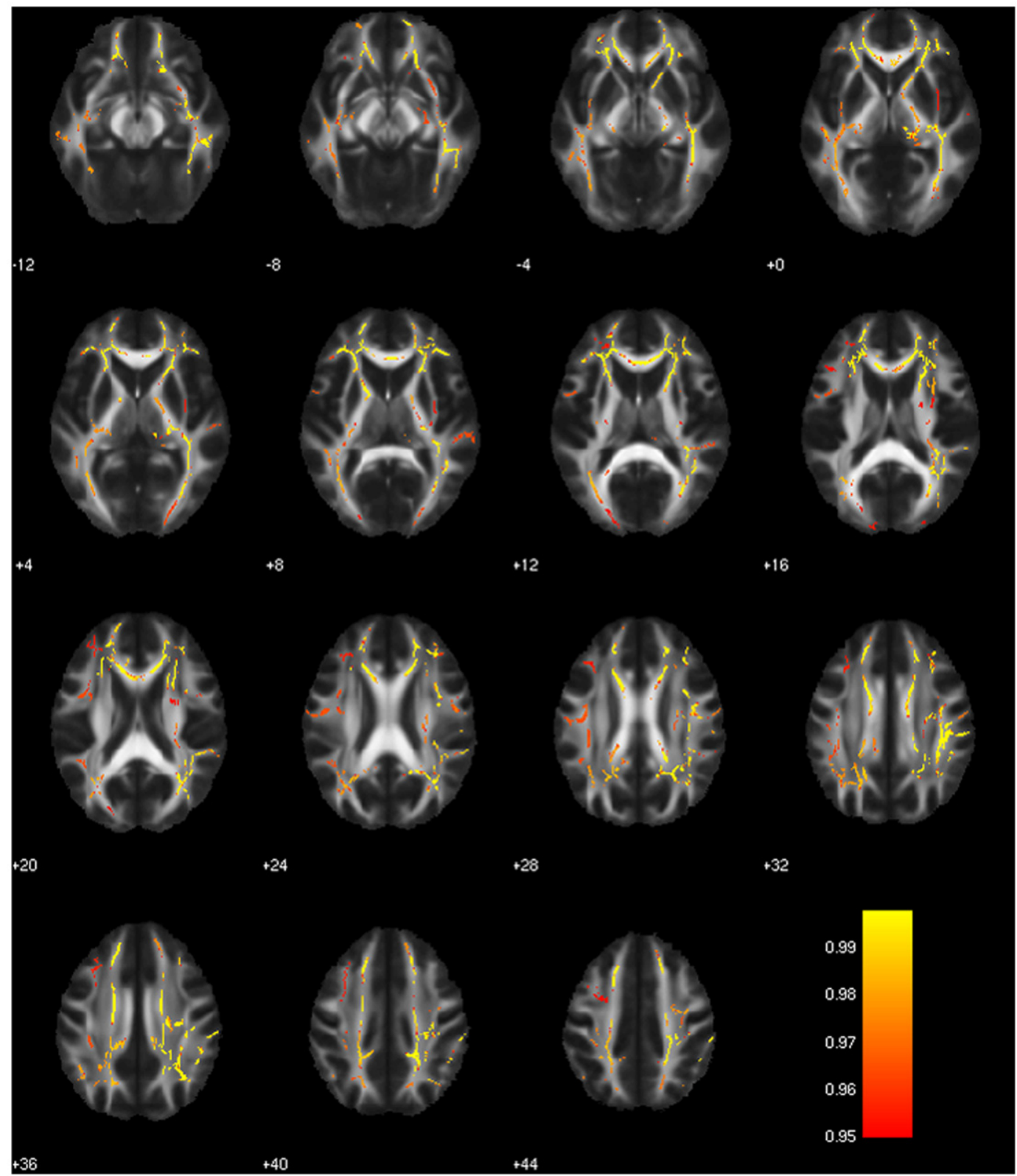

Figure 2 White matter areas where drug treated patients had significantly lower values of fractional anisotropy (FA) than healthy controls. Voxels of significant difference are shown on the mean FA template of the studied sample. The colorbar refers to 1- $p$ values for the observed differences. Group differences are mapped onto the mean FA brain template. Numbers are $z$ coordinates in the standard Montreal Neurological Institute (MNI) space. Images are in neurologic convention (left side of the brain is represented on the left side of the pictures). (For interpretation of the references to color in this figure legend, the reader is referred to the web version of this article.)

correlation between reduced FA and the therapeutic effects of drug treatments suggests that changes in WM microstructure, as detected by DTI, could be part of their mechanism of action.

Recent perspectives emphasized the therapeutic relevance of the effects of psychotropic drugs on myelination and lipid homeostasis (Bartzokis, 2011; Bartzokis et al., 2009; Vik-Mo et al., 2009). Antidepressants can modify membrane fluidity and lipid composition (Zschocke et al., 2011), thus leading to accumulation of phospholipids in lysosomes (Xia et al., 2000) and promoting autophagy in astrocytes and neurons (Zschocke et al., 2011). In cultured human glial cells, commonly used antipsychotics and antidepressants can stimulate cellular lipogenesis (Raeder et al., 2006), activate cholesterol transport and efflux pathways, also involving apolipoprotein $E$ (ApoE) (Vik-Mo et al., 2009), and modify the intracellular trafficking of cholesterol (Kristiana et al., 2010). ApoE and cholesterol are essential for myelin generation and repair (Dietschy and Turley, 2004), and to regulate synaptic plasticity in the adult brain (Barres and Smith, 2001; Mauch et al., 2001). Cholesterol enrichment in myelin sheaths reduces water binding and allows a tight membrane packing (Bartzokis, 2011), thus decreasing water permeability (Mathai et al., 2008). 


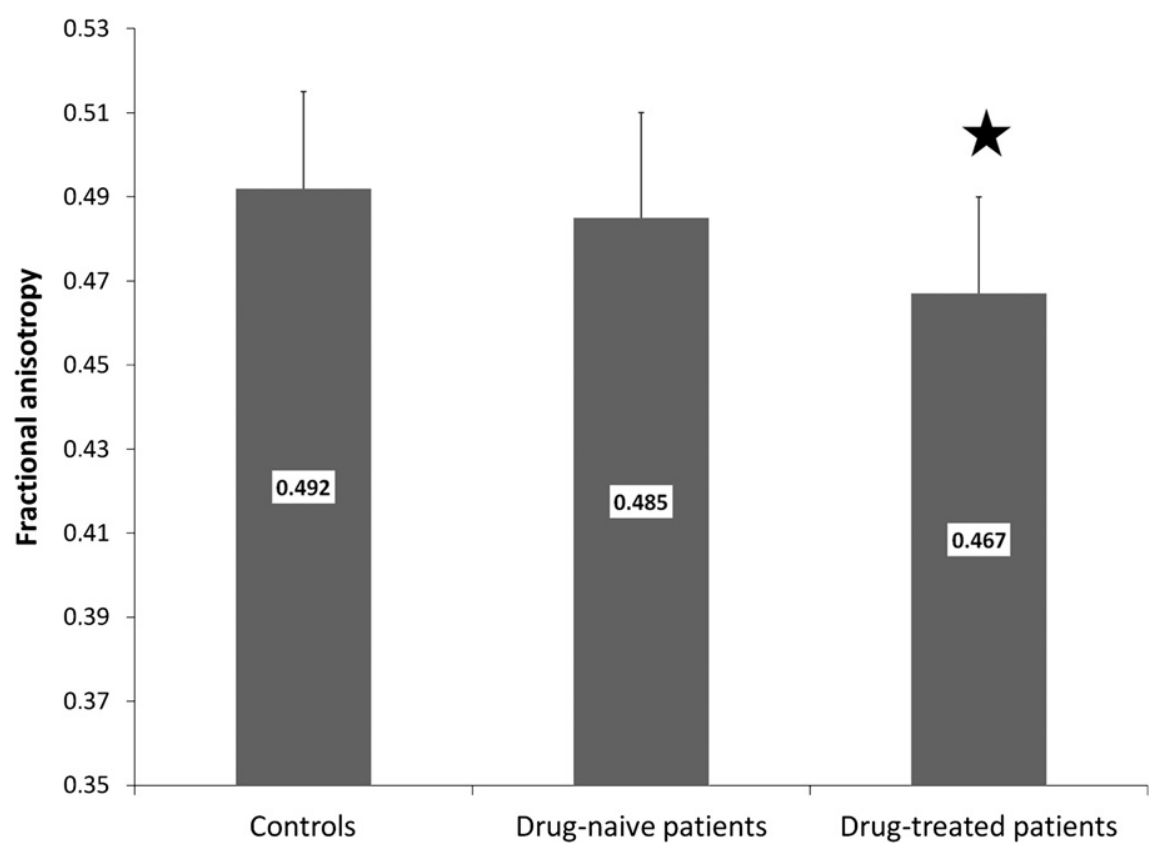

Figure 3 Fractional anisotropy values of the sample divided according to diagnosis and treatment. Values are means \pm standard errors, and are presented for the regions where patients differed from healthy controls (see Table 3 for details). * $p<0.05$ vs. Controls (corrected for multiple comparisons).

Moreover, many neurotransmitters (including dopamine, serotonin, and noradrenaline) are released out of the synapse and can be involved in regulation of oligodendrocyte differentiation or remyelination (Bartzokis, 2011). Glutamate is released from synaptic collaterals on glial cells, thus probably regulating oligodendrocyte differentiation or remyelination (Gallo, 2007; Kukley et al., 2007; Ziskin et al., 2007). The proliferation and differentiation of developing oligodendrocytes, and their myelination of axons, are partly controlled by neurotransmitters, with membrane potentials of oligodendrocytes being influenced by dopamine, serotonin, noradrenaline, GABA, glutamate, glycine, acetilcholine (Karadottir and Attwell, 2007). The accepted hallmarks of remyelination are the presence of short internodes and of sheaths that are inappropriately thin for the size of the enclosed axons (Peters, 2009).

Drug-induced changes in glial lipid and cholesterol metabolism and trafficking, together with enhanced autophagy and remyelination/regenerating processes of oligodendrocytes, could lead to changes in the structure of cell membranes and myelin sheaths resulting in changes of their biophysical properties, such as water diffusion. Moreover, signaling pathways downstream the direct targets of psychotropics used in OCD, such as Akt and glycogen synthase kinase-3, can affect myelination, its plasticity, and repair (Bartzokis, 2012).

Following the above line of reasoning, the widespread changes of DTI measures observed in our OCD patients might not necessarily be an index of WM pathology, but could reflect a yet unexplored part of the mechanism of action of drugs used in their treatment, or be a marker of their biological effect on the brain. This hypothesis is supported by the only existing prospective study performed in drugnaïve patients (Yoo et al., 2007), and by recent studies showing that OCD symptom severity positively correlated with increased FA in various WM tracts (Li et al., 2011; Zarei et al., 2011): a drug-induced reduction of FA could then be part of the mechanism of action of drug treatments of OCD.

Nevertheless, this perspective is highly speculative because existing animal models have well correlated DTI measures with WM lesions, but not with the physiological processes listed above or with the course of psychiatric illness and treatment. Notwithstanding this limitation, we think however that our results warrant interest for the prospective study of DTI measures as major biological markers during the treatment of OCD.

Finally, the lack of observed differences between drugnaive patients and healthy controls does not imply a lack of correlation between OCD symptomatolgical dimensions and DTI measures of WM structure. Previous studies affirmed that different OCD symptoms can be clustered into dimensions that probably have different neural substrates (Gilbert et al., 2008; Mataix-Cols et al., 1999, 2004; van den Heuvel et al., 2009), possibly including differences in WM structure. Negative correlations have been described between FA and ordering/obsessing symptoms, but not with checking, washing, hoarding or neutralizing, in the corpus callosum and the cingulate bundle (Koch et al., 2012) and between Y-BOCS scores and FA in parietal regions (Szeszko et al., 2005), but also positive correlations between obsessive subscale scores and FA in the left middle temporal gyrus (Li et al., 2011) and in the anterior cingulum bundle (Ha et al., 2009). A study in monozygotic twins discordant or concordant for OCD symptoms suggested that environmental risk for OCD was associated with an increase in dorsolateral-prefrontal FA, while the genetic risk was associated with a decrease in inferior frontal FA (den Braber et al., 2011), thus also raising the issue of gene-environment interactions in modulating the relationship between OCD symptomatology and DTI measures of WM structure. These issues could not be addressed in the present study, because the size of our sample was 
Table 3 Comparison of drug-treated OCD patients with healthy controls and with drug-naïve OCD patients. Regions showing maximal differences of TBSS values (signal peaks). Values of the DTI measures of FA, MD and RD (means $\pm S D$ ) are shown for all groups in the WM regions where the drug-treated patients significantly differed from healthy controls, or from drug-naïve patients. Dimensions of clusters (number of voxels, $\mathrm{mm}^{3}$ ), Z-values, and involved WM tracts are shown for regions showing maximal differences of TBSS values (signal peaks, MNI coordinates) between patients and controls.

\begin{tabular}{|c|c|c|c|c|c|}
\hline & Controls & Patients & $\begin{array}{l}\text { Number of } \\
\text { voxels }\end{array}$ & $\begin{array}{l}\text { Signal peak }(x, y, z) \text { and } \\
\text { corresponding } Z \text { values }\end{array}$ & White matter tracts \\
\hline \multicolumn{6}{|c|}{ Regions where drug-treated patients differed from healthy controls } \\
\hline $\begin{array}{l}\text { Fractional anisotropy } \\
\text { (patients }<\text { controls) }\end{array}$ & $0.491963 \pm 0.106451$ & $\begin{array}{l}\text { all patients: } 0.475002 \pm 0.107743 \\
\text { drug-naïve: } 0.484686 \pm 0.107723 \\
\text { drug-treated: } 0.467078 \pm 0.108311\end{array}$ & 31,978 & $\begin{array}{l}-1637-5 \\
Z=3.030\end{array}$ & $\begin{array}{l}\text { Anterior corona radiata } L \\
\text { Forceps minor } \\
\text { Inferior fronto-occipital fasciculus } L \\
\text { Uncinate fasciculus } L\end{array}$ \\
\hline \multirow[t]{6}{*}{$\begin{array}{c}\text { Mean diffusivity } \\
\text { (patients }>\text { controls) }\end{array}$} & $7.33 \pm 0.45$ & $\begin{array}{l}\text { all patients: } 7.52 \pm 0.45 \\
\text { drug-naïve: } 7.42 \pm 0.45\end{array}$ & 36,170 & $\begin{array}{l}-162824 \\
Z=2.605\end{array}$ & $\begin{array}{l}\text { Anterior corona radiata } \mathrm{L} \\
\text { Cingulate bundle } \mathrm{L}\end{array}$ \\
\hline & & drug-treated: $7.60 \pm 0.46$ & 279 & $\begin{array}{l}56-617 \\
Z=2.437\end{array}$ & Superior longitudinal fasciculus $\mathrm{R}$ \\
\hline & & & 186 & $\begin{array}{l}-31-77-12 \\
Z=3.036\end{array}$ & $\begin{array}{l}\text { Inferior longitudinal fasciculus } \mathrm{L} \\
\text { Inferior fronto-occipital fasciculus } \mathrm{L}\end{array}$ \\
\hline & & & 157 & $\begin{array}{l}-12-9511 \\
Z=2.748\end{array}$ & $\begin{array}{l}\text { Forceps major } \\
\text { Inferior fronto-occipital fasciculus } L \\
\text { Inferior longitudinal fasciculus } L\end{array}$ \\
\hline & & & 119 & $\begin{array}{l}-34-2-32 \\
Z=2.382\end{array}$ & Inferior longitudinal fasciculus $\mathrm{L}$ \\
\hline & & & 116 & $\begin{array}{l}1749-9 \\
Z=2.326\end{array}$ & $\begin{array}{l}\text { Anterior thalamic radiation } \mathrm{R} \\
\text { Inferior fronto-occipital fasciculus } \mathrm{R} \\
\text { Forceps minor } \\
\text { Uncinate fasciculus }\end{array}$ \\
\hline $\begin{array}{c}\text { Radial diffusivity } \\
\text { (patients > controls) }\end{array}$ & $5.29 \pm 0.67$ & $\begin{array}{l}\text { all patients: } 5.50 \pm 0.69 \\
\text { drug-naïve: } 5.38 \pm 0.70 \\
\text { drug-treated: } 5.59 \pm 0.70\end{array}$ & 42,396 & $\begin{array}{l}-1433-4 \\
Z=3.09\end{array}$ & $\begin{array}{l}\text { Anterior corona radiata } \\
\text { Forceps minor } \\
\text { Inferior fronto-occipital fasciculus } R / L \\
\text { Uncinate fasciculus } L\end{array}$ \\
\hline \multicolumn{6}{|c|}{ Regions where drug-treated patients differed from drug-naïve patients } \\
\hline $\begin{array}{l}\text { Fractional anisotropy } \\
\text { (patients }<\text { controls) }\end{array}$ & $0.477884 \pm 0.65132$ & $\begin{array}{l}\text { all patients: } 0.465779 \pm 0.65005 \\
\text { drug-naïve: } 0.484096 \pm 0.65163 \\
\text { drug-treated: } 0.450793 \pm 0.65289\end{array}$ & 2297 & $\begin{array}{l}26-5525 \\
Z=2.620\end{array}$ & $\begin{array}{l}\text { Inferior fronto-occipital fasciculus R; } \\
\text { Inferior longitudinal fasciculus R } \\
\text { Superior longitudinal fasciculus R }\end{array}$ \\
\hline $\begin{array}{c}\text { Radial diffusivity } \\
\text { (patients }>\text { controls) }\end{array}$ & $5.11 \pm 0.62$ & $\begin{array}{l}\text { all patients: } 5.27 \pm 0.63 \\
\text { drug-naïve: } 5.08 \pm 0.64 \\
\text { drug-treated: } 5.43 \pm 0.64\end{array}$ & 9774 & $\begin{array}{l}-152421 \\
Z=2.23\end{array}$ & $\begin{array}{l}\text { Genu corpus callosum; } \\
\text { Forceps minor } \\
\text { Cingulate gyrus L }\end{array}$ \\
\hline
\end{tabular}


adequate to detect differences due to drug status, but clearly not sufficient to correlate the complex symptoms dimensions to WM structure in drug-naive $(n=18)$. Our results (1) confirm the interest for the study of WM structure in OCD psychopatology, by suggesting that effective drugs influence it, and (2) suggest that future studies aimed at elucidating this relationship will need to take into account the drug status of the patients.

Limitations of the present study, which is correlational in nature, also include issues such as generalizability, possible population stratification, mixed contents of obsessions and compulsions, concomitant medications and their effects on the observed differences, no placebo control, no evaluation for compliance, varying treatment periods, without consideration of gene-environment interactions, and technical issues such as slice thickness that could limit the specificity of the regional differences, or specific issues related to TBSS which limits the study of the WM tracts which are out of the centers the fiber bundles (the WM skeleton).

\section{Role of funding source}

No specific funding for this study.

The C.E.R.M.A.C. received research Grants from the Italian Ministry of University and Scientific Research, from the Italian Ministry of Health, from the European Union (FP7 Grant 222963), from Trenta ore per la Vita Association, and from Janssen-Cilag.

\section{Contributors}

All individuals included as authors of papers contributed substantially to the scientific process leading up to the writing of the paper. FB designed the study. ES, FB, and AF obtained the funding. SD, EP and ES were involved in the participants' recruitment and the selection. EP and SD collected the clinical data. DR and SP carried out the brain imaging scanning with the neuroradiological supervision of AF. CG designed the TBSS-TFCE data analyses and carried it out with the contributions from FB. FB wrote the first draft of the manuscript, with other authors contributing to data interpretation and final manuscript preparation. All authors take final responsibility for the decision to submit for publication. FB and CG had full access to all of the data in the study and take responsibility for the integrity of the data and the accuracy of the data analysis. The authors are entirely responsible for the scientific content of the paper.

\section{Conflict of interest}

None of the authors have financial disclosures or conflicts of interest pertinent to the contents of the manuscript.

\section{Appendix A. Supplementary material}

Supplementary data associated with this article can be found in the online version at doi:10.1016/j.euroneuro. 2012.07.002.

\section{References}

Alexander, A.L., Lee, J.E., Lazar, M., Field, A.S., 2007. Diffusion tensor imaging of the brain. Neurotherapeutics 4, 316-329.
Atmaca, M., Onalan, E., Yildirim, H., Yuce, H., Koc, M., Korkmaz, S., 2010. The association of myelin oligodendrocyte glycoprotein gene and white matter volume in obsessive-compulsive disorder. J. Affect. Disord. 124, 309-313.

Barres, B.A., Smith, S.J., 2001. Neurobiology. Cholesterol-making or breaking the synapse. Science 294, 1296-1297.

Bartzokis, G., 2011. Neuroglialpharmacology: white matter pathophysiologies and psychiatric treatments. Front. Biosci. 17, 2695-2733.

Bartzokis, G., 2012. Neuroglialpharmacology: myelination as a shared mechanism of action of psychotropic treatments. Neuropharmacology 62, 2137-2153.

Bartzokis, G., Lu, P.H., Stewart, S.B., Oluwadara, B., Lucas, A.J., Pantages, J., Pratt, E., Sherin, J.E., Altshuler, L.L., Mintz, J., Gitlin, M.J., Subotnik, K.L., Nuechterlein, K.H., 2009. In vivo evidence of differential impact of typical and atypical antipsychotics on intracortical myelin in adults with schizophrenia. Schizophr. Res. 113, 322-331.

Blumenthal, J.D., Zijdenbos, A., Molloy, E., Giedd, J.N., 2002. Motion artifact in magnetic resonance imaging: implications for automated analysis. Neuroimage 16, 89-92.

Bora, E., Harrison, B.J., Fornito, A., Cocchi, L., Pujol, J., Fontenelle, L.F., Velakoulis, D., Pantelis, C., Yucel, M., 2011. White matter microstructure in patients with obsessive-compulsive disorder. J. Psychiatry Neurosci. 36, 42-46.

Bullmore, E.T., Suckling, J., Overmeyer, S., Rabe-Hesketh, S., Taylor, E., Brammer, M.J., 1999. Global, voxel, and cluster tests, by theory and permutation, for a difference between two groups of structural MR images of the brain. IEEE Trans. Med. Imaging 18, 32-42.

Cannistraro, P.A., Makris, N., Howard, J.D., Wedig, M.M., Hodge, S.M., Wilhelm, S., Kennedy, D.N., Rauch, S.L., 2007. A diffusion tensor imaging study of white matter in obsessive-compulsive disorder. Depress. Anxiety 24, 440-446.

Chamberlain, S.R., Blackwell, A.D., Fineberg, N.A., Robbins, T.W., Sahakian, B.J., 2005. The neuropsychology of obsessive compulsive disorder: the importance of failures in cognitive and behavioural inhibition as candidate endophenotypic markers. Neurosci. Biobehav. Rev. 29, 399-419.

Chao, T.C., Chou, M.C., Yang, P., Chung, H.W., Wu, M.T., 2009. Effects of interpolation methods in spatial normalization of diffusion tensor imaging data on group comparison of fractional anisotropy. Magn. Reson. Imaging 27, 681-690.

Chiu, C.H., Lo, Y.C., Tang, H.S., Liu, I.C., Chiang, W.Y., Yeh, F.C., Jaw, F.S., Tseng, W.Y., 2011. White matter abnormalities of fronto-striato-thalamic circuitry in obsessive-compulsive disorder: a study using diffusion spectrum imaging tractography. Psychiatry Res. 192, 176-182.

den Braber, A., van't Ent, D., Boomsma, D.I., Cath, D.C., Veltman, D.J., Thompson, P.M., de Geus, E.J., 2011. White matter differences in monozygotic twins discordant or concordant for obsessive-compulsive symptoms: a combined diffusion tensor imaging/voxel-based morphometry study. Biol. Psychiatry 70, 969-977.

Dietschy, J.M., Turley, S.D., 2004. Thematic review series: brain lipids. Cholesterol metabolism in the central nervous system during early development and in the mature animal. J. Lipid Res. 45, 1375-1397.

Duran, F.L., Hoexter, M.Q., Valente Jr., A.A., Miguel, E.C., Busatto, G.F., 2009. Association between symptom severity and internal capsule volume in obsessive-compulsive disorder. Neurosci. Lett. 452, 68-71.

El Mansari, M., Blier, P., 2006. Mechanisms of action of current and potential pharmacotherapies of obsessive-compulsive disorder. Prog. Neuropsychopharmacol. Biol. Psychiatry 30, 362-373.

Engvig, A., Fjell, A.M., Westlye, L.T., Moberget, T., Sundseth, O., Larsen, V.A., Walhovd, K.B., 2011. Memory training impacts short-term changes in aging white matter: a longitudinal 
diffusion tensor imaging study. Hum. Brain Mapp. http://dx.doi. org/10.1002/hbm.21370. [Epub ahead of print].

Fineberg, N.A., Potenza, M.N., Chamberlain, S.R., Berlin, H.A., Menzies, L., Bechara, A., Sahakian, B.J., Robbins, T.W., Bullmore, E.T., Hollander, E., 2010. Probing compulsive and impulsive behaviors, from animal models to endophenotypes: a narrative review. Neuropsychopharmacology 35, 591-604.

Fitzgerald, K.D., Stern, E.R., Angstadt, M., Nicholson-Muth, K.C., Maynor, M.R., Welsh, R.C., Hanna, G.L., Taylor, S.F., 2010. Altered function and connectivity of the medial frontal cortex in pediatric obsessive-compulsive disorder. Biol. Psychiatry 68, 1039-1047.

Fontenelle, L.F., Bramati, I.E., Moll, J., Medlowicz, M.V., de Oliveira-Souza, R., Tovar-Moll, F., 2011. White matter changes in OCD revealed by diffusion tensor imaging. CNS Spectrums. CNS Spectr. 2011 May 1. pii: Fontenelle. [Epub ahead of print].

Fontenelle, L.F., Harrison, B.J., Yucel, M., Pujol, J., Fujiwara, H., Pantelis, C., 2009. Is there evidence of brain white-matter abnormalities in obsessive-compulsive disorder?: a narrative review. Top. Magn. Reson. Imaging 20, 291-298.

Gallo, V., 2007. Surprising synapses deep in the brain. Nat. Neurosci. 10, 267-269.

Garibotto, V., Scifo, P., Gorini, A., Alonso, C.R., Brambati, S., Bellodi, L., Perani, D., 2010. Disorganization of anatomical connectivity in obsessive compulsive disorder: a multi-parameter diffusion tensor imaging study in a subpopulation of patients. Neurobiol. Dis. 37, 468-476.

Gilbert, A.R., Mataix-Cols, D., Almeida, J.R., Lawrence, N., Nutche, J., Diwadkar, V., Keshavan, M.S., Phillips, M.L., 2008. Brain structure and symptom dimension relationships in obsessive-compulsive disorder: a voxel-based morphometry study. J. Affect. Disord. 109, 117-126.

Goodman, W.K., Price, L.H., Rasmussen, S.A., Mazure, C., Fleischmann, R.L., Hill, C.L., Heninger, G.R., Charney, D.S., 1989. The Yale-Brown obsessive compulsive scale. I. Development, use, and reliability. Arch. Gen. Psychiatry 46, 1006-1011.

Ha, T.H., Kang, D.H., Park, J.S., Jang, J.H., Jung, W.H., Choi, J.S., Park, J.Y., Jung, M.H., Choi, C.H., Lee, J.M., Ha, K., Kwon, J.S., 2009. White matter alterations in male patients with obsessivecompulsive disorder. Neuroreport 20, 735-739.

Harrison, B.J., Soriano-Mas, C., Pujol, J., Ortiz, H., Lopez-Sola, M., Hernandez-Ribas, R., Deus, J., Alonso, P., Yucel, M., Pantelis, C., Menchon, J.M., Cardoner, N., 2009. Altered corticostriatal functional connectivity in obsessive-compulsive disorder. Arch. Gen. Psychiatry 66, 1189-1200.

Herting, M.M., Maxwell, E.C., Irvine, C., Nagel, B.J., 2011. The impact of sex, puberty, and hormones on white matter microstructure in adolescents. Cereb. Cortex. 2011 Oct 14. [Epub ahead of print].

Hoeft, F., Barnea-Goraly, N., Haas, B.W., Golarai, G., Ng, D., Mills, D., Korenberg, J., Bellugi, U., Galaburda, A., Reiss, A.L., 2007. More is not always better: increased fractional anisotropy of superior longitudinal fasciculus associated with poor visuospatial abilities in Williams syndrome. J. Neurosci. 27, 11960-11965.

Horsfield, M.A., Jones, D.K., 2002. Applications of diffusionweighted and diffusion tensor MRI to white matter diseases-a review. NMR Biomed. 15, 570-577.

Jang, J.H., Kim, J.H., Jung, W.H., Choi, J.S., Jung, M.H., Lee, J.M., Choi, C.H., Kang, D.H., Kwon, J.S., 2010. Functional connectivity in fronto-subcortical circuitry during the resting state in obsessive-compulsive disorder. Neurosci. Lett. 474, 158-162.

Jenkinson, M., Smith, S., 2001. A global optimisation method for robust affine registration of brain images. Med. Image Anal. 5, 143-156.

Karadottir, R., Attwell, D., 2007. Neurotransmitter receptors in the life and death of oligodendrocytes. Neuroscience 145, 1426-1438.
Koch, K., Wagner, G., Schachtzabel, C., Schultz, C.C., Straube, T., Gullmar, D., Reichenbach, J.R., Peikert, G., Sauer, H., Schlosser, R.G., 2012. White matter structure and symptom dimensions in obsessive-compulsive disorder. J. Psychiatr. Res. 46, 264-270.

Kochunov, P., Thompson, P.M., Lancaster, J.L., Bartzokis, G., Smith, S., Coyle, T., Royall, D.R., Laird, A., Fox, P.T., 2007. Relationship between white matter fractional anisotropy and other indices of cerebral health in normal aging: tract-based spatial statistics study of aging. Neuroimage 35, 478-487.

Konopaske, G.T., Dorph-Petersen, K.A., Sweet, R.A., Pierri, J.N., Zhang, W., Sampson, A.R., Lewis, D.A., 2008. Effect of chronic antipsychotic exposure on astrocyte and oligodendrocyte numbers in macaque monkeys. Biol. Psychiatry 63, 759-765.

Koprivova, J., Horacek, J., Tintera, J., Prasko, J., Raszka, M., Ibrahim, I., Hoschl, C., 2009. Medial frontal and dorsal cortical morphometric abnormalities are related to obsessivecompulsive disorder. Neurosci. Lett. 464, 62-66.

Kristiana, I., Sharpe, L.J., Catts, V.S., Lutze-Mann, L.H., Brown, A.J., 2010. Antipsychotic drugs upregulate lipogenic gene expression by disrupting intracellular trafficking of lipoproteinderived cholesterol. Pharmacogenomics J. 10, 396-407.

Kukley, M., Capetillo-Zarate, E., Dietrich, D., 2007. Vesicular glutamate release from axons in white matter. Nat. Neurosci. 10, 311-320.

Le Bihan, D., 2003. Looking into the functional architecture of the brain with diffusion MRI. Nat. Rev. Neurosci. 4, 469-480.

Li, F., Huang, X., Yang, Y., Li, B., Wu, Q., Zhang, T., Lui, S., Kemp, G.J., Gong, Q., 2011. Microstructural brain abnormalities in patients with obsessive-compulsive disorder: diffusion-tensor MR imaging study at 3.0 T. Radiology 260, 216-223.

Linden, D.E., 2006. How psychotherapy changes the brain-the contribution of functional neuroimaging. Mol. Psychiatry 11 , 528-538.

Lochner, C., Fouche, J.P., du Plessis, S., Spottiswoode, B., Seedat, S., Fineberg, N., Chamberlain, S.R., Stein, D.J., 2012. Evidence for fractional anisotropy and mean diffusivity white matter abnormalities in the internal capsule and cingulum in patients with obsessive-compulsive disorder. J. Psychiatry Neurosci. 37, 193-199.

Mataix-Cols, D., Rauch, S.L., Manzo, P.A., Jenike, M.A., Baer, L., 1999. Use of factor-analyzed symptom of dimensions to predict outcome with serotonin reuptake inhibitors and placebo in the treatment of obsessive-compulsive disorder. Am. J. Psychiatry 156, 1409-1416.

Mataix-Cols, D., Wooderson, S., Lawrence, N., Brammer, M.J., Speckens, A., Phillips, M.L., 2004. Distinct neural correlates of washing, checking, and hoarding symptom dimensions in obsessive-compulsive disorder. Arch. Gen. Psychiatry 61, 564-576.

Mathai, J.C., Tristram-Nagle, S., Nagle, J.F., Zeidel, M.L., 2008. Structural determinants of water permeability through the lipid membrane. J. Gen. Physiol. 131, 69-76.

Mauch, D.H., Nagler, K., Schumacher, S., Goritz, C., Muller, E.C., Otto, A., Pfrieger, F.W., 2001. CNS synaptogenesis promoted by glia-derived cholesterol. Science 294, 1354-1357.

Menzies, L., Williams, G.B., Chamberlain, S.R., Ooi, C., Fineberg, N., Suckling, J., Sahakian, B.J., Robbins, T.W., Bullmore, E.T., 2008. White matter abnormalities in patients with obsessive compulsive disorder and their first-degree relatives. Am. J. Psychiatry 165, 1308-1315.

Nakamae, T., Narumoto, J., Sakai, Y., Nishida, S., Yamada, K., Nishimura, T., Fukui, K., 2011. Diffusion tensor imaging and tract-based spatial statistics in obsessive-compulsive disorder. J. Psychiatr. Res. 45, 687-690.

Nakamae, T., Narumoto, J., Shibata, K., Matsumoto, R., Kitabayashi, Y., Yoshida, T., Yamada, K., Nishimura, T., Fukui, K., 2008. Alteration of fractional anisotropy and apparent diffusion 
coefficient in obsessive-compulsive disorder: a diffusion tensor imaging study. Prog. Neuropsychopharmacol. Biol. Psychiatry 32, 1221-1226.

Nichols, T.E., Holmes, A.P., 2002. Nonparametric permutation tests for functional neuroimaging: a primer with examples. Hum. Brain Mapp. 15, 1-25.

Oh, J.S., Jang, J.H., Jung, W.H., Kang, D.H., Choi, J.S., Choi, C.H., Kubicki, M., Shenton, M.E., Kwon, J.S., 2011. Reduced frontocallosal fiber integrity in unmedicated OCD patients: a diffusion tractography study. Hum. Brain Mapp. http://dx.doi.org/10. 1002/hbm.21372. [Epub ahead of print].

Park, H.Y., Park, J.S., Kim, S.H., Jang, J.H., Jung, W.H., Choi, J.S., Kang, D.H., Lee, J.M., Kwon, J.S., 2011. Midsagittal structural differences and sexual dimorphism of the corpus callosum in obsessive-compulsive disorder. Psychiatry Res. 192, 147-153.

Peters, A., 2009. The effects of normal aging on myelinated nerve fibers in monkey central nervous system. Front. Neuroanat. $3,11$.

Pierpaoli, C., Barnett, A., Pajevic, S., Chen, R., Penix, L.R., Virta, A., Basser, P., 2001. Water diffusion changes in Wallerian degeneration and their dependence on white matter architecture. Neuroimage 13, 1174-1185.

Raeder, M.B., Ferno, J., Glambek, M., Stansberg, C., Steen, V.M., 2006. Antidepressant drugs activate SREBP and up-regulate cholesterol and fatty acid biosynthesis in human glial cells. Neurosci. Lett. 395, 185-190.

Remijnse, P.L., Nielen, M.M., van Balkom, A.J., Cath, D.C., van Oppen, P., Uylings, H.B., Veltman, D.J., 2006. Reduced orbitofrontal-striatal activity on a reversal learning task in obsessive-compulsive disorder. Arch. Gen. Psychiatry 63, 1225-1236.

Rose, S.E., Hatzigeorgiou, X., Strudwick, M.W., Durbridge, G., Davies, P.S., Colditz, P.B., 2008. Altered white matter diffusion anisotropy in normal and preterm infants at term-equivalent age. Magn. Reson. Med. 60, 761-767.

Rueckert, D., Sonoda, L.I., Hayes, C., Hill, D.L., Leach, M.O., Hawkes, D.J., 1999. Nonrigid registration using free-form deformations: application to breast MR images. IEEE Trans. Med. Imaging 18, 712-721.

Saito, Y., Nobuhara, K., Okugawa, G., Takase, K., Sugimoto, T., Horiuchi, M., Ueno, C., Maehara, M., Omura, N., Kurokawa, H., Ikeda, K., Tanigawa, N., Sawada, S., Kinoshita, T., 2008. Corpus callosum in patients with obsessive-compulsive disorder: diffusion-tensor imaging study. Radiology 246, 536-542.

Sakai, Y., Narumoto, J., Nishida, S., Nakamae, T., Yamada, K., Nishimura, T., Fukui, K., 2010. Corticostriatal functional connectivity in non-medicated patients with obsessive-compulsive disorder. Eur. Psychiatry 26, 463-469.

Smith, S.M., 2002. Fast robust automated brain extraction. Hum. Brain Mapp. 17, 143-155.

Smith, S.M., Jenkinson, M., Johansen-Berg, H., Rueckert, D., Nichols, T.E., Mackay, C.E., Watkins, K.E., Ciccarelli, O., Cader, M.Z., Matthews, P.M., Behrens, T.E., 2006. Tract-based spatial statistics: voxelwise analysis of multi-subject diffusion data. Neuroimage 31, 1487-1505.

Smith, S.M., Jenkinson, M., Woolrich, M.W., Beckmann, C.F., Behrens, T.E., Johansen-Berg, H., Bannister, P.R., De Luca, M., Drobnjak, I., Flitney, D.E., Niazy, R.K., Saunders, J., Vickers, J., Zhang, Y., De Stefano, N., Brady, J.M., Matthews, P.M., 2004. Advances in functional and structural MR image analysis and implementation as FSL. Neuroimage 23 (Suppl. 1), S208-219.

Smith, S.M., Johansen-Berg, H., Jenkinson, M., Rueckert, D., Nichols, T.E., Miller, K.L., Robson, M.D., Jones, D.K., Klein, J.C., Bartsch, A.J., Behrens, T.E., 2007. Acquisition and voxelwise analysis of multi-subject diffusion data with tract-based spatial statistics. Nat. Protoc. 2, 499-503.

Smith, S.M., Nichols, T.E., 2009. Threshold-free cluster enhancement: addressing problems of smoothing, threshold dependence and localisation in cluster inference. Neuroimage 44, 83-98.
Song, S.K., Sun, S.W., Ramsbottom, M.J., Chang, C., Russell, J., Cross, A.H., 2002. Dysmyelination revealed through MRI as increased radial (but unchanged axial) diffusion of water. Neuroimage 17, 1429-1436.

StatSoft, I., 1995. STATISTICA per Windows. StatSoft Italia srl.

Steffens, D.C., Chung, H., Krishnan, K.R., Longstreth Jr., W.T., Carlson, M., Burke, G.L., 2008. Antidepressant treatment and worsening white matter on serial cranial magnetic resonance imaging in the elderly: the cardiovascular health study. Stroke 39, 857-862.

Stern, E.R., Welsh, R.C., Fitzgerald, K.D., Gehring, W.J., Lister, J.J., Himle, J.A., Abelson, J.L., Taylor, S.F., 2011. Hyperactive error responses and altered connectivity in ventromedial and frontoinsular cortices in obsessive-compulsive disorder. Biol. Psychiatry 69, 583-591.

Szeszko, P.R., Ardekani, B.A., Ashtari, M., Malhotra, A.K., Robinson, D.G., Bilder, R.M., Lim, K.O., 2005. White matter abnormalities in obsessive-compulsive disorder: a diffusion tensor imaging study. Arch. Gen. Psychiatry 62, 782-790.

Taylor, W.D., Macfall, J.R., Boyd, B., Payne, M.E., Sheline, Y.I., Krishnan, R.R., Murali Doraiswamy, P., 2011. One-year change in anterior cingulate cortex white matter microstructure: relationship with late-life depression outcomes. Am. J. Geriatr. Psychiatry 19, 43-52.

Togao, O., Yoshiura, T., Nakao, T., Nabeyama, M., Sanematsu, H., Nakagawa, A., Noguchi, T., Hiwatashi, A., Yamashita, K., Nagao, E., Kanba, S., Honda, H., 2010. Regional gray and white matter volume abnormalities in obsessive-compulsive disorder: a voxelbased morphometry study. Psychiatry Res. 184, 29-37.

van den Heuvel, O.A., Remijnse, P.L., Mataix-Cols, D., Vrenken, H., Groenewegen, H.J., Uylings, H.B., van Balkom, A.J., Veltman, D.J., 2009. The major symptom dimensions of obsessivecompulsive disorder are mediated by partially distinct neural systems. Brain 132, 853-868.

van den Heuvel, O.A., Veltman, D.J., Groenewegen, H.J., Cath, D.C., van Balkom, A.J., van Hartskamp, J., Barkhof, F., van Dyck, R., 2005. Frontal-striatal dysfunction during planning in obsessivecompulsive disorder. Arch. Gen. Psychiatry 62, 301-309.

Versace, A., Almeida, J.R., Hassel, S., Walsh, N.D., Novelli, M., Klein, C.R., Kupfer, D.J., Phillips, M.L., 2008. Elevated left and reduced right orbitomedial prefrontal fractional anisotropy in adults with bipolar disorder revealed by tract-based spatial statistics. Arch. Gen. Psychiatry 65, 1041-1052.

Vik-Mo, A.O., Ferno, J., Skrede, S., Steen, V.M., 2009. Psychotropic drugs up-regulate the expression of cholesterol transport proteins including ApoE in cultured human CNS and liver cells. BMC Pharmacol. 9, 10.

Westlye, L.T., Walhovd, K.B., Dale, A.M., Bjornerud, A., DueTonnessen, P., Engvig, A., Grydeland, H., Tamnes, C.K., Ostby, Y., Fjell, A.M., 2010. Life-span changes of the human brain white matter: diffusion tensor imaging (DTI) and volumetry. Cereb. Cortex 20, 2055-2068.

Woolrich, M.W., Jbabdi, S., Patenaude, B., Chappell, M., Makni, S., Behrens, T., Beckmann, C., Jenkinson, M., Smith, S.M., 2009. Bayesian analysis of neuroimaging data in FSL. Neuroimage 45, S173-186.

Xia, Z., Ying, G., Hansson, A.L., Karlsson, H., Xie, Y., Bergstrand, A., DePierre, J.W., Nassberger, L., 2000. Antidepressant-induced lipidosis with special reference to tricyclic compounds. Prog. Neurobiol. 60, 501-512.

Yoo, S.Y., Jang, J.H., Shin, Y.W., Kim, D.J., Park, H.J., Moon, W.J., Chung, E.C., Lee, J.M., Kim, I.Y., Kim, S.I., Kwon, J.S., 2007. White matter abnormalities in drug-naive patients with obsessivecompulsive disorder: a diffusion tensor study before and after citalopram treatment. Acta Psychiatr. Scand. 116, 211-219.

Zarei, M., Mataix-Cols, D., Heyman, I., Hough, M., Doherty, J., Burge, L., Winmill, L., Nijhawan, S., Matthews, P.M., James, A., 2011. Changes in gray matter volume and white matter 
microstructure in adolescents with obsessive-compulsive disorder. Biol. Psychiatry 70, 1083-1090.

Zhang, T., Wang, J., Yang, Y., Wu, Q., Li, B., Chen, L., Yue, Q., Tang, H., Yan, C., Lui, S., Huang, X., Chan, R.C., Zang, Y., He, Y., Gong, Q., 2011. Abnormal small-world architecture of top-down control networks in obsessive-compulsive disorder. J. Psychiatry Neurosci. 36, 23-31.
Ziskin, J.L., Nishiyama, A., Rubio, M., Fukaya, M., Bergles, D.E., 2007. Vesicular release of glutamate from unmyelinated axons in white matter. Nat. Neurosci. 10, 321-330.

Zschocke, J., Zimmermann, N., Berning, B., Ganal, V., Holsboer, F., Rein, T., 2011. Antidepressant drugs diversely affect autophagy pathways in astrocytes and neurons-dissociation from cholesterol homeostasis. Neuropsychopharmacology 36, 1754-1768. 